\title{
PENERAPAN PEMBELAJARAN TEAMS GAMES TOURNAMENT (TGT) DILENGKAPI KARTU NAMA DARI TATA NAMA SENYAWA KIMIA UNTUK MENINGKATKAN HASIL BELAJAR SISWA
}

\author{
Opir Rumape ${ }^{1}$, Nelpiani Christopel ${ }^{2}$, Jafar La Kilo ${ }^{3}$, dan Akram La Kilo ${ }^{4}$ \\ 123,4 Universitas Negeri Gorontalo, Kota Goontalo, Indonesia
}

\section{A R T I C L E I N F O} Article history:

Received 23 Februari 2020 Received in revised form

26 Februari 2020

Accepted 28 Maret 2020

Available online 30 April 2020

Kata Kunci:

TGT, Hasil Belajar,Kartu

Nama, Tata Nama Senyawa Kimia.

\begin{abstract}
A B S T R A K
Penelitian ini bertujuan untuk meningkatkan hasil belajar siswa pada materi tata nama senyawa kimia menggunakan model pembelajaran Teams Games Tournament (TGT) berbasis media kartu nama. Hasil belajar yang diukur yaitu aspek kognitif, aspek afektif, dan aspek psikomotor. Desain penelitian yang digunakan adalah true experimental design dengan pretest-posttest control group design. Sampel dalam penelitian ini berjumlah 53 siswa masing-masing pada kelas eksperimen sebanyak 26 siswa dan kelas kontrol sebanyak 30 siswa. Kelas eksperimen menggunakan model pembelajran TGT berbantuan media kartu nama sedangkan pada kelas kontrol menggunakan model pembelajaran konvensional. Hasil uji validitas tes menunjukkan bahwa 15 soal valid dan hasil reliabitas tes adalah 0,92 tergolong dalam kategori tinggi. Hasil pengujian hipotesis menggunakan uji-t dengan separated varian. Hasil tesebut menunjukkan bahwa pada taraf signifikan 0,05 dengan $\mathrm{dk}=51$ diperoleh thitung 4,01 > Ttabel 1,67, maka H0 ditolak dan H1 diterima. Hal ini menunjukkan bahwa terdapat pengaruh model pembelajaran kooperatif tipe Teams Games Tournament (TGT) dilengkapi media kartu nama terhadap hasil belajar dengan nilai rata-rata yang diperoleh pada kelas eksperimen sebesar 62,57 dan pada kelas kontrol 53,58. Hasil aspek afektif dari kedua kelas dikategorikan baik, ratarata kelas eksperimen 82,2\% sedangkan pada kelas kontrol 73,8\%. Pada Aspek psikomotor dari kedua kelas dikategorikan terampil, rata-rata pada aspek psikomotor antara kelas eksperimen 81,9\% dan kelas kontrol adalah 69,2\%.
\end{abstract}

\begin{abstract}
This study aimed to improve student learning outcomes on chemical compound nomenclature using Teams Games Tournament (TGT) learning model based on card media. Learning outcomes measured are cognitive aspects, affective aspects, and psychomotor aspects. The research design used was true experimental design with pretestposttest control group design. The sample in this study amounted to 53 students, 26 students in experimental class by and 30 students at control class. The experimental class used the TGT learning model assisted by card media while the control class used a conventional learning model. The test results show that the validity of the 15 valid questions and the reliability of the test results is 0.92 in the high category. The results of testing the hypothesis using the $t$-test with separated variants. The results showed that at a significant level was 0.05 with $\mathrm{dk}=51$ tcount was $4.01>$ Ttable 1.67, then $\mathrm{H} 0$ was rejected and $\mathrm{H} 1$ was accepted. This showed that there is an influence of the Teams Games Tournament (TGT) type of cooperative learning model equipped with card media on learning outcomes with an average score in the experimental class was 62.57 and in control class was 53.58. The results of the affective aspects of both classes are good, the average experimental class was $82.2 \%$ while the control class was $73.8 \%$. In the psychomotor aspect of the two classes categorized as skilled, the average in the psychomotor aspect between the experimental class was $81.9 \%$ and the control class was $69.2 \%$.
\end{abstract}

Keywords: TGT, Learning Outcomes, Cards, Nomenclature for Chemical Compounds..

\footnotetext{
1 Corresponding author.

E-mail: akram@ung.ac.id (Opir Rumape)
} 


\section{Pendahuluan}

Permasalahan klasik dalam pembelajaran kimia adalah banyaknya siswa yang berpendapat bahwa kimia merupakan mata pelajaran yang sulit untuk dipahami sehingga berdampak pada hasil belajar siswa yang rendah. Salah satu penyebab dari keadaan ini adalah kesulitan memahami konsep-konsep kimia yaitu ketidakmampuan menghubungkan dunia makroskopis dan mikroskopis (Arsyad et al., 2016; Bait et al., 2018). Selain itu, banyak konsep-konsep kimia yang bersifat abstrak dan merupakan mata pelajaran yang secara khusus baru dipelajari pada tingkat SMA. Siswa pun cenderung belajar dengan metode hafalan daripada secara aktif mencari tahu dan membangun pemahaman mereka sendiri terhadap konsep ilmu kimia (La Kilo, 2017; Maksum et al., 2017; Monoarfa et al., 2017).

Hasil observasi dan wawancara yang telah dilakukan di SMA Negeri 1 Telaga adalah hasil belajar siswa pada mata pelajaran kimia masih sangat rendah di bawah Kriteria Ketuntasan Minimal (KKM) Kimia. Siswa menggangap materi pembelajaran kimia sulit, apalagi bukan pilihan utama siswa dalam belajar. Proses pembelajaran kimia di kelas kurang menarik, sehingga siswa merasa jenuh dan kurang memiliki minat pada pelajaran kimia. Suasana kelas pun cenderung pasif, siswa enggan bertanya pada guru meskipun materi yang diajarkan belum dapat dipahami. Keadaan demikian menimbulkan kebosanan, sehingga perhatian, minat, dan motivasi siswa dalam pembelajaran menjadi rendah, dan menyebabkan ketidaktercapaian tujuan pembelajaran kimia. Hal ini sejalan dengan hasil pembeljaran kimia yang dilaporkan oleh (Muderawan et al., 2019). Oleh karena itu perlu dicari solusi yang membuat siswa terlibat aktif dalam proses pembelajaran. Salah satunya adalah menerpakan pembelajaran Teams Games Tournament (TGT).

Model pembelajaran TGT memadukan unsur edukasi dan permainan, serta mengandung unsur turnamen sehingga peserta didik lebih tertantang dan bersemangat dalam mengikuti pelajaran(Mamanda and Sumantri, 2018). Adanya permainan dan turnamen dalam pembelajaran juga menjadikan pembelajaran tidak membosankan, mendorong siswa untuk lebih berani mengemukakan pendapat di depan kelas, melatih siswa bekerja sama dalam tim, dan meningkatkan daya saing siswa dalam pembelajaran kimia (Susanna, 2018). Pembejaran model TGT ini dapat meningkatkan motivasi dan hasil belajar siswa pada materi kimia (Qurrota and Suardana, 2017; Zumaroh et al., 2017; Sugiata, 2019). Agar pembelajaran TGT dapat dikontrol dengan baik, maka dibuat peta konsep atau media kartu (Salman et al., 2017; Hidanurhayati et al., 2018). Bentuk dan jenis kartu disesuiakan dengan kondisi siswa dan materi ajar agar tujuan pembelajaran dapat tercapai (Suprapto, 2013).

Penelitin ini bertujuan untuk meningkatkan hasil belajar siswa SMA Negeri 1 Telaga melalui pembelajaran TGT berbasis kartu nama tatanama senyawa. Kartu nama tersebut memuat nama-nama senyawa kimia baik organik maupun organik serta beberapa nama menurut aturan IUPAC. Hasil belajar yang dimaksud terdiri dari pengetahuan, sikap, dan psikomor baik pada kelas eksperimen maupun kelas kontrol. Karena kedua kelas tersebut dibandingkan hasilnya, maka artikel ini juga menentukan pengaruh pembelajaran TGT tersebut dibandingkan dengan pembelajaran konvensional.

\section{Metode}

Penelitian ini dilaksanakan di SMA Negeri 1 Telaga pada tahun pelajaran 2019/2020. Sampel penelitan ini sebanyak 53 iswa yang terdiri dari adalah 27 siswa kelas X MIA 6 sebagai kelas kontrol dan 26 siswa kelas X MIA 7 sebagai kelas eksperimen. Penelitian ini menggunakan desain penelitian quasi experimental, yaitu pretest-posttest nonequivalent control group sebagaimana ditunjukkan pada Tabel 1.

Tabel 1 Pretest-Posttest Non Equivalent Control Group Design

\begin{tabular}{ccccc}
\hline Kelas & & Pretest & Perlakuan & Posttest \\
\hline & Eksperimen & $\mathrm{O}_{1}$ & $\mathrm{X}_{1}$ & $\mathrm{O}_{3}$ \\
& Kontrol & $\mathrm{O}_{2}$ & $\mathrm{X}_{2}$ & $\mathrm{O}_{4}$ \\
\hline
\end{tabular}

dimana:

$\mathrm{X}_{1}$ : Perlakuan model Team Games Tournament berbantuan media kartu nama

$\mathrm{X}_{2}$ : Perlakuan model konvensional

Pengumpulan data penelitian menggunakan instrumen tes dan angket. Instrumen tes berupa 15 soal tes objektif yang memuat indikator penerapan aturan tata nama senyawa anorganik dan organik serta penentuan beberapa senyawa sesuai aturan IUPAC. Sementara, angket digunakan untuk mengetahui sikap dan psikimotor siswa. Intstrumen tes telah valid dan reliabel berdasarkan uji validitas dan reliabel yang masing-masing menggunakan rumus korelasi biserial dan koefisien alfa sebgaimana yang dilakukan oleh Laliyo et al. (2020). 
Data hasil penelitian dianalisis untuk mengetahuai pengaruh pembelajaran model TGT berbasis media kartu nama tatanama senyawa kimia dan megetahui peninhkatan hasil belajar siswa baik pengetahuan, afektif, maupun psikomotor. Pengaruh pembelajaran melalui pengujian hipotesi dengan ujit dengan rumus polled varians:

$$
t_{\text {hitung }}=\frac{\bar{x}_{1}-\bar{x}_{2}}{\sqrt[s]{\frac{1}{n_{1}}+\frac{1}{n_{2}}}}
$$

dimana:

$t_{\text {hitung }}=$ nilai hitung untuk uji- $t$

$n_{1}=$ jumlah responden kelas eksperimen

$n_{2}=$ jumlah responden kelas kontrol

$\bar{x}_{1}=$ nilai rata-rata kelas eksperimen

$\bar{x}_{2}=$ nilai rata-rata kelas kontrol

$\mathrm{S}=$ varians

H0 : Tidak ada pengaruh penggunaan model pembelajaran TGT berbasis kartu nama tatanama senyawa kimia terhadap hasil belajar siswa kelas X SMA Negeri 1 Telaga.

H1 : Terdapat pengaruh penggunaan model pembelajaran TGT berbasis kartu nama tatanama senyawa kimia terhadap hasil belajar siswa kelas X SMA Negeri 1 Telaga.

Data hasil belajar siswa berupa skor tes yang diperoleh melalui tes tertentu berbentuk soal objektif untuk mengetahui kemampuan siswa diawal (pretest) dan diakhir (posttest) pembelajaran. Secara individual, hasil belajar peserta didik dikatakan telah tuntas belajar jika mencapai KKM 70 dengan perhitungan sebagai berikut:

skor peserta didik $=\frac{\text { jumlah skoryang diperoleh }}{\text { skor maksimum }} \times 100 \%$

Nilai ketercapaian siswa dengan rentang antara 0 sampai 100 dikategorikan menjadi 5 taraf keberhasilan seperti yang tertera dalam Tabel 2.

Tabel 2. Kategori Taraf Keberhasilan Aspek Pengetahuan, Sikap, dan Psikomotor Siswa

Skor Peserta Didik Taraf Keberhasilan Nilai dengan Huruf

\begin{tabular}{ccc}
\hline $0-29$ & Sangat kurang & E \\
$30-64$ & Kurang & D \\
$65-74$ & Cukup & C \\
$75-84$ & Baik & B \\
$85-100$ & Sangat baik & A \\
\hline
\end{tabular}

\section{Hasil dan pembahasan}

1) Model Pembelajaran TGT berbasis Kartu Nama Tatanama Senyawa Kimia

Model pembelajaran TGT berbasis kartu ini memiliki 5 tahap pembelajaran yaitu, (1) presentasi di kelas, (2) pembentukan tim, (3) permainan (games), (4) turnamen, (5) kesimpulan. Presentasi di kelas dipimpin oleh guru dengan memberikan pertanyaan-pertanyaan pada awal pembelajaran. Pertanyaan ini mengarahkan pada permasalahan yang akan dibahas. Pertanyaan ini dapat merangsang pengetahuan awal siswa terhadap materi yang akan diajarkan. Berdasarkan observasi, beberapa siswa yang antusias dalam menjawab pertanyaan yang diajukan oleh guru dan hal ini membuat siswa menjadi lebih aktif saat pembelajaran. Dalam pembentukan pembentukan tim, guru membagi siswa menjadi 4 kelompok yang terdiri dari 5-6 siswa. Setelah itu, guru mengarahkan siswa cara permainan TGT menggunakan media kartu nama tatanama senyawa kimia sehingga tidak terjadi kesalahan dalam memainkan game.

Game dilakukan dengan menggunakan media kartu nama, dimana kartu tersebut berisikan soal dan jawabannya terkait materi yang diajarkan. Setiap kelompok diuji kecepatan dan ketelitian dalam kerjasama memainkan game. Permainan dilakukan dengan cara guru memberikan kartu kepada setiap 
kelompok. Kartu yang diberikan berisikan soal dan jawaban. Setiap kelompok diberi waktu dalam memainkan game. Turnamen, siswa memainkan game sesuai dengan pentunjuk yang diberikan oleh guru. Game dimainkan dengan cara siswa mendengarkan setiap pertanyaan yang dibacakan oleh guru kepada masing-masing kelompok, setelah itu siswa mencari jawaban dari pertanyaan di meja turnamen yang telah disiapkan. Apabila pertanyaan dari kelompok yang diberikan kesempatan menjawab tidak dapat dijawab, maka pertanyaan dilemparkan kepada kelompok lain. demikian seterusnya. Kesimpulan, tahap ini merupakan tahap akhir dimana masing-masing kelompok diminta untuk membuat kesimpulan, guru meminta perwakilan dari dari tiap kelompok untuk memberikan kesimpulan dari proses pembelajaran.

\section{2) Pengujian Hipotesis}

Pengujian hipotesis dilakukan setelah uji normalitas dan uji homogenitas. Uji normalitas menggunakan rumus Liliefors dengan taraf signifikan $\alpha=0,05$. Hasil uji yang diperoleh baik kelas ekpsperimen maupun kelas kontrol adalah terdistribusi normal sebagiaman disajikan pada Tabel 3.

Tabel 3. Uji Normalitas Pretest dan Posttest Kelas Eksperimen dan Kelas Kontrol

\begin{tabular}{cccccc}
\hline Kelas & Tes & N & Lhitung & Ltabel & Keterangan \\
\hline Kontrol & Pretest & 27 & 0,16 & 0,1706 & Normal \\
& Posttest & 27 & 0,15 & 0,1706 & Normal \\
Eksperimen & Pretest & 26 & 0,16 & 0,173 & Normal \\
& Posttest & 26 & 0,13 & 0,173 & Normal \\
\hline
\end{tabular}

Sedangakan uji homogenitas kedua sampel menggunakan uji fisher pada taraf signifikan $5 \%(\alpha=0,05)$. Hasil uji tersebut adalah homogen sebagaimana ditunjukkan pada Tabel 4.

Tabel 4. Uji Homogenitas Pretest dan Posttest Kelas Eksperimen dan Kelas Kontrol

\begin{tabular}{|c|c|c|c|c|}
\hline Kelas & Tes & $F_{\text {hitung }}$ & $F_{\text {tabel }}$ & Keterangan \\
\hline Kontrol & Pretest & 1,62 & 1,94 & Homogen \\
\hline Eksperimen & Pretest & & & Homogen \\
\hline $\begin{array}{c}\text { Kontrol } \\
\text { Eksperimen }\end{array}$ & $\begin{array}{l}\text { Posttest } \\
\text { Posttest }\end{array}$ & 1,03 & 1,94 & $\begin{array}{l}\text { Homogen } \\
\text { Homogen }\end{array}$ \\
\hline
\end{tabular}

Setelah kedua sampel dinyatakan terdistribusi normal dan homogen, maka uji-t terpenuhi untuk dilakukan. Berdasarkan hasil perhitungan diperoleh nilai $t_{\text {hitung }}$ sebesar 4,01 dan nilai $t_{\text {tabel }}$ pada $\alpha=0,05$; $\mathrm{dk}=(\mathrm{n} 1+\mathrm{n} 2-2=51)$ adalah 1,67. Dengan demikian $t_{\text {hitung }}$ lebih besar daripada $t_{\text {tabel }}$ sehingga, H0 ditolak dan $\mathrm{H} 1$ diterima. Hal ini berarti bahwa terdapat pengaruh penggunaan model pembelajaran TGT berbasis kartu nama tatanama senyawa kimia terhadap hasil belajar siswa kelas X SMA Negeri 1 Telaga.

\section{3) Hasil Belajar}

Hasil belajar yang disajikan di sini adalah hasil belajar kognitif, sikap, dan psikomotor baik pada kelas eksperimen maupun kelas kontrol. Hasil tes kognitif siswa pada pretest adalah di bawah KKM, dimana rata-rata nilai yang diperoleh kelas eksperimen dan kelas kontrol masing-masing adalah 45,63 dan 37,04. Nilai tersebut merupakan gambaran kemampuan awal siswa sebelum diberikan pembelajaran baik konvensional maupun model pembelajaran TGT berbesas kartu nama tatanama senyawa kimia. Setelah diberikan pembelajaran, maka nilaai kognitif kedua kelas tersebut meningkat dengan hasil rata-rata kelas eksperimen 62,57 dan kelas kontrol 53,58. Kedua nilai tersebut tidak memenuhi KKM, namun hasil tersebut menunjukkan bahwa model pembelajaran Teams Games Tournament (TGT) berbasis kartu nama tatanama senyawa kimia lebih baik daripada model pembelajaran konvesional.

Nilai tertinggi kelas eksperimen adalah 80 yang diperoleh oleh 3 siswa, sementara nilai tertinggi untuk kelas kontrol adalah 73,3 yang diraih oleh 2 orang siswa sebagaimana ditunjukkan pada Gambar 1. Gambaran nilai kelas ekperimen tersebut masih dibawa nilai pembelajaran TGT yang dilaporkan oleh (Susanti et al., 2016; Damayanti and Apriyanto, 2017; Rahmawati, 2017). Hal tersebut diakibatkan oleh kekurangan pada tahap 4 (turnamen) dari TGT berbasis kartu ini, yaitu siswa mencari jawaban yang tertulis pada kartu berdasarkan sola yang dibacakan oleh guru. Padahal, sebaiknya, siswa menuliskan jawaban pada kartu yang diberikan sehingga dengan cepat jawaban diketahui, dan tidak banyak membuang waktu. Oleh karena itu, guru pun menjadi sumber yang menyebabkan rendahnya nilai siswa pada kelas eksperime. Hal ini sejalan dengan yang dilaporkan oleh Muderawan et al.(2019) bahwa salah satu faktor yang menyebbakan rendahnya nilai kimia siswa adalah guru kurang baik dalam mendesai pembelajaran. 


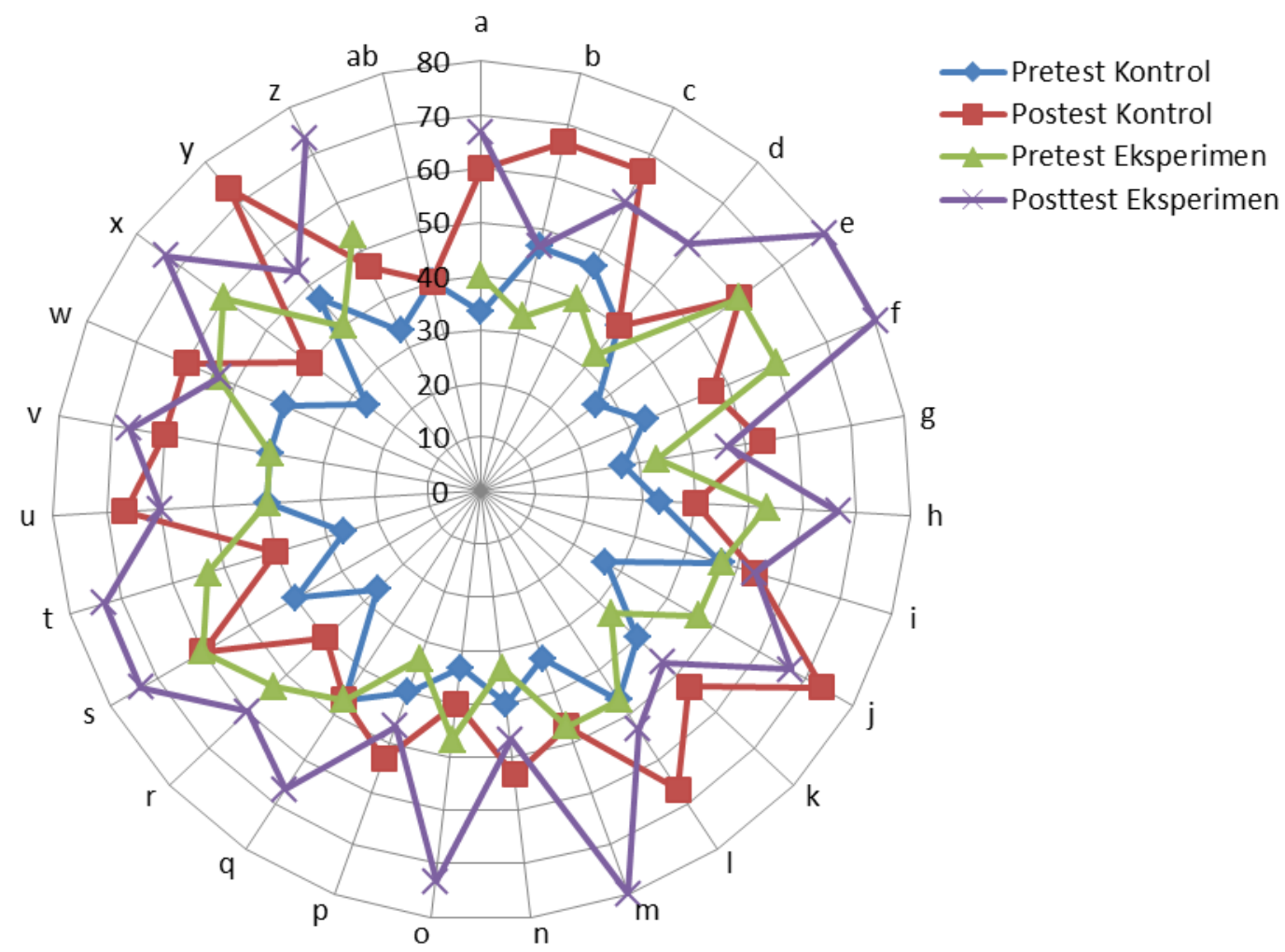

Gambar 1. Data Hasil Pretest dan Posttest Kelas Eksperimen dan Kelas Kontrol

Kognitif kelas eksperimen yang lebih tinggi dibandingakan dengan kelas kontrol didukung didukung dengan nilai afektif dan psikomotor. Afektif siswa pada kelas eksperimen lebih tinggi dibandingkan dengan kelas control. Jumlah rata-rata nilai afektif siswa pada kelas eksperimen adalah sebesar 82,21 sehingga berdasarkan rubrik penilaian afektif siswa pada kelas eksperimen termasuk dalam kategori baik. Sedangkan untuk kelas kontrol jumlah rata-rata nilai afektif siswa adalah sebesar 73,84 dan termasuk dalam kategori cukup.

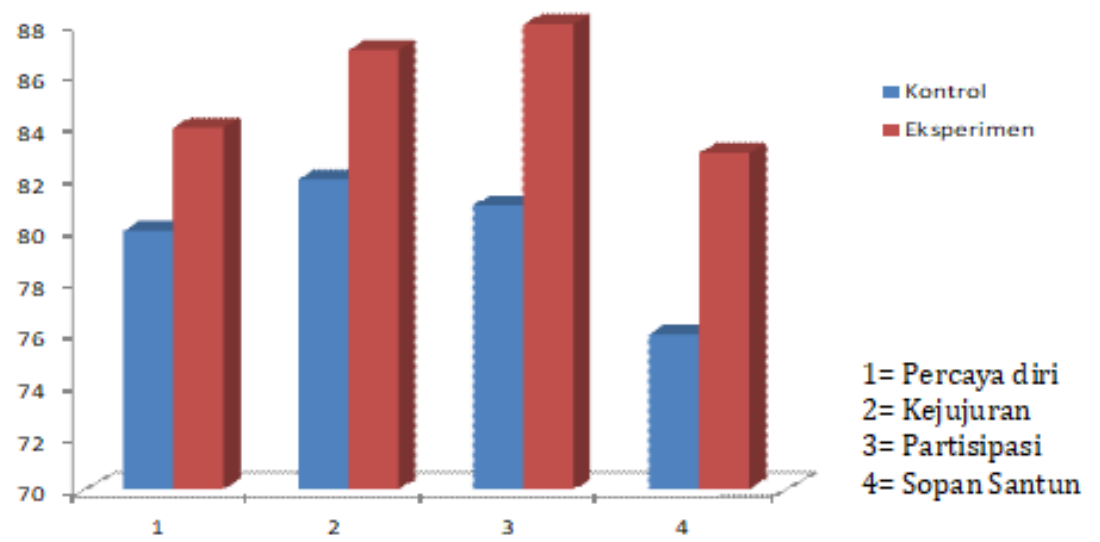

Gambar 2. Hasil perbandingan nilai Aspek Afektif siswa Kelas Eksperimen dan Kelas Kontrol

Sejalan dengan aspek afektif, nilai nilai rata-rata psikomotor siswa pada kelas eksperimen pun lebih tinggi daripada kelas kontrol. Jumlah rata-rata yang diperoleh kelas eksperimen adalah sebesar 81,97 sehingga termasuk dalam kriteria baik sedangkan untuk kelas kontrol memperoleh rata-rata nilai psikomotor sebesar 69,21 sehingga termaasuk dalam kriteria cukup. 
Pembelajaran Teams Games Tournament (TGT) menuntut siswa untuk mampu bekerja sama sehingga adanya hubungan antara masing-masing anggota untuk menyelesaikan masalah yang diberikan oleh guru dengan bantuan media yang telah diberikan. Hubungan antara siswa dan guru pada kedua kelas telah berlangsung dengan baik. Pembelajaran kooperatif Teams Games Tournament (TGT) umumnya menuntut kesiapan siswa dan keaktifan siswa selama proses pembelajaran sehingga penggunaan model kooperatif Teams Games Tournament (TGT) dapat meningkatkan hasil belajar siswa meliputi aspek kognitif, afektif, dan psikomotor. Selama pengamatan keadaan siswa di dalam kelas pada pembelajaran kooperatif dilengkapi dengan media kartu nama lebih kondusif jika dibandingkan pada kelas yang menggunakan pembelajaran konvesional. Hal ini terlihat bahwa kepercayaan diri, kejujuran, partisipasi, dan sopan santun lebih baik pada kelas eksperimen dibandingkan dengan kelas kontrol. Kelas eksperimen lebih aktif dan antusias dalam kegiatan pembelajaran maupun dalam menyelesaikan soal-soal secara tim sedangkan pada kelas kontrol minat siswa terlihat kurang karena malas dalam kegiatan pembelajaran yang hanya menggunakan model ceramah disertai tanya jawab, sehingga hanya guru yang terlihat aktif sedangkan siswa pasif

\section{Simpulan dan saran}

Hasil penelitian yang telah dilakukan menunjukkan bahwa penerapan model pembelajaran Teams Games Tournament (TGT) dilengkapi media kartu nama tatanama senyawa kimia lebih baik dibadingkan model pembelajaran konvensional. Hal ini terbukti dari hasil belajar kognitif, afektif, dan psikomotor kelas eksperimen lebih baik daripada kelas kontrol. Guru yang kurang baik dalam mendesain pembelajaran, khususnya dalam tahap turnamen dari TGT menyebabkan nilai siswa rendah yang tidak mencapai KKM. Oleh karena itu, penerapan model pembelajaran TGT yang berbasis media sebaiknya didesain sedemikian rupa agar pelaksnaannya terkontrol dengan baik baik dari segi siswa maupun waktu.

\section{Daftar Rujukan}

Arsyad M. A. M., Sihaloho M., and La Kilo A., (2016), Analisis Miskonsepsi pada Konsep Hidrolisis Garam Siswa Kelas XI SMAN 1 Telaga. Jambura J. Educ. Chem., 11(2), 190-195.

Bait D. J., Duengo S., and La Kilo A., (2018), Pengaruh Model Pembelajaran Simayang Tipe II terhadap Peningkatan Kemampuan Representasi Kimia Siswa Kelas X pada Materi Larutan Elektrolit dan Nonelektrolit di SMA Terpadu Wira Bhakti Gorontalo. Jambura J. Educ. Chem., 13(2), 157-163.

Damayanti S. and Apriyanto M. T., (2017), PENGARUH MODEL PEMBELAJARAN KOOPERATIF TIPE TGT (TEAMS GAMES TOURNAMENT) TERHADAP HASIL BELAJAR MATEMATIKA How to Cite (APA 6 th Style. (02), 235-244.

Hidanurhayati H., Sihaloho M., and La Kilo A., (2018), Pengaruh Model Pembelajaran Numbered Heads Together (NHT) Disertai Media Kartu Pintar terhadap Prestasi Belajar Siswa pada Materi Larutan Penyangga Kelas XI di SMA Negeri 1 Kabila. Jambura J. Educ. Chem., 13(2), 233-240.

La Kilo A., (2017), Solusi Rumus Derajat Keasaman Reaksi Asam Basa pada Larutan Penyangga dengan Metode Mol Awal (Rumus Akram). PATEN, 8(1065).

Laliyo L. A. R., Kau M., La Kilo J., and La Kilo A., (2020), KEMAMPUAN SISWA MEMECAHKAN MASALAH HUKUM-HUKUM DASAR KIMIA MELALUI PEMBELAJARAN INKUIRI TERBIMBING. AR-RAZI J. Ilm., 8(1), 1-8.

Maksum M. J., Sihaloho M., and La Kilo A., (2017), Analisis Kemampuan Pemahaman Siswa pada Konsep Larutan Penyangga Menggunakan Three Tier Multiple Choice Tes. Jambura J. Educ. Chem., 12(1), 47-53.

Mamanda S. and Sumantri M., (2018), Penerapan Model Pembelajaran Kooperatif Tipe Teams GamesTournament dengan Menggunakan Media Kartu Cetak untuk Meningkatkan Hasil Belajar. J. Educ. Action Res., 2(4), 348-354.

Monoarfa Z. P., La Kilo A., and Botutihe D. N., (2017), Identifikasi Miskonsepsi Siswa Kelas XI IPA 1 di SMA Negeri 3 Gorontalo Utara pada Konsep Larutan Penyangga. Jambura J. Educ. Chem., 12(2), 215223. 
Muderawan I. W., Wiratma I. G. L., and Nabila M. Z., (2019), ANALISIS FAKTOR-FAKTOR PENYEBAB KESULITAN BELAJAR SISWA PADA PELAJARAN KIMIA. J. Pendidik. Kim. Indones., 3(1), 17-23.

Qurrota D. and Suardana I. N., (2017), Penerapan Model Pembelajaran Kooperatif Tipe TGT (Teams Games Tournament) untuk Meningkatkan Motivasi dan Hasil Belajar Peserta Didik. J. Pendidik. Kim. Indones., 1(2).

Rahmawati N. K., (2017), Implementasi Teams Games Tournaments dan Number Head Together ditinjau dari Kemampuan Penalaran Matematis,.

Salman L., Suleman N., and La Kilo A., (2017), Pengaruh Model Pembelajaran Project Based Learning (PjBL) yang Disertai dengan Peta Konsep terhadap Hasil Belajar Siswa Kelas XI TPHP SMK Negeri 2 Gorontalo pada Materi Sistem Koloid. Jambura J. Educ. Chem., 12(2), 193-200.

Sugiata I. W., (2019), Penerapan Model Pembelajaran Team Game Tournament (Tgt) Untuk Meningkatkan Hasil Belajar. J. Pendidik. Kim. Indones., 2(2), 78.

Suprapto A. N., (2013), PERMAINAN MONOPOLI SEBAGAI MEDIA UNTUK MENINGKATKANMINAT BELAJAR TATA BOGA DI SMA. J. Ilm. Guru Caraka Olah Pikir Edukatif, (1).

Susanna S., (2018), Penerapan Teams Games Tournament (TGT) Melalui Media Kartu Domino Pada Materi Minyak Bumi Siswa Kelas XI MAN 4 Aceh Besar. Lantanida J., 5(2), 93-105.

Susanti F., Ayub S., and Taufik M., (2016), Perbedaan Hasil Belajar Fisika Melalui Model Pembelajaran Kooperatif Tipe Numbered Heads Together (NHT) Berbantuan Kartu Soal dengan Model Pembelajaran Direct Instruction Di SMAN 7 Mataram Tahun Ajaran 2015/2016,.

Zumaroh E., Widana I. D., and Muliani N. L., (2017), Penerapan model pembelajaran kooperatif tipe teams games tournament (TGT) pada pembelajaran kimia untuk meningkatkan motivasi dan hasil belajar siswa. J. Pendidik. Kim. Indones., 1(1), 30-36. 